\title{
A semiautomated microfluidic platform for real-time investigation of nanoparticles' cellular uptake and cancer cells' tracking
}

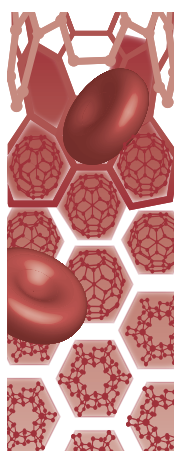

\begin{abstract}
Aim: Develop a platform composed of labeled dendrimer nanoparticles (NPs) and a microfluidic device for real-time monitoring of cancer cells fate. Materials \& methods: Carboxymethylchitosan/poly(amidoamine) dendrimer NPs were labeled with fluorescein-5(6)-isothiocyanate and characterized using different physicochemical techniques. After, HeLa, HCT-116 and U87MG were cultured in the presence of NPs, and cell viability and internalization efficiency in static (standard culture) and dynamic (microfluidic culture) conditions were investigated. Results: Cancer cells cultured with NPs in dynamic conditions were viable and presented higher internalization levels as compared with static 2D cultures. Conclusion: This work demonstrated that the proposed microfluidic-based platform allows real-time monitoring, which upon more studies, namely, the assessment of an anticancer drug release effect could be used for cancer theranostics.
\end{abstract}

First draft submitted: 26 September 2016; Accepted for publication: 11 January 2017; Published online: 10 February 2017

Keywords: cell tracking $\bullet$ circulating tumor cells $\bullet$ microfluidics $\bullet$ nanoparticles

- theranostics

Cancer is a major cause of mortality, being directly responsible for $1,665,540$ new cancer cases and 585,720 cancer deaths in the USA in 2014 [1]. Its incidence is estimated to increase up to 13 million by 2030 , worldwide [2]. The metastasis process, where circulating tumor cells (CTCs) migrate and colonize distant organs, is responsible for about $90 \%$ of deaths [3]. Thus, CTCs have been highly studied, and new information has arisen regarding its fate and subsequent host interaction, the importance of shear stress and real-time visualization in understanding these processes [4]. New strategies for cancer diagnosis and treatment have become more sophisticated and high-throughput processes have been applied due to forward-thinking nanotechnology techniques, such as the use of nanoparticles (NPs). In fact, NP can be modified to target-specific cells, as CTCs, and induce specific cancer cell death [5]. Addi- tionally, these nanometer-sized structures are very attractive for health-related applications, as they can be rationally designed taking advantage of the cut-off pore size of the vasculature, in other words, enhanced permeation and retention effect, allowing these to be used for imaging, diagnosis and therapy, holding great promise in the cancer field $[6,7]$. The possibility of being designed on demand is one of the major advantages of such nanotools. In this reasoning, they can be used both in the preparation of cell-tracking tools (such as migration patterns and response to physical and chemical factors) and the visualization of delivery and distribution of drugs in real time [8]. Recently, imaging tools such as microscopy images obtained in static 2D conditions have been used to determine abnormal cellular distribution patterns [9], which could indicate loss of adherence, a crucial step for cancer pro-
Mariana R Carvalho, , , F Raquel Maia, ${ }^{1,2}$, Joana SilvaCorreia ${ }^{1,2}$, Bruno M Costa ${ }^{2,3}$, Rui L Reis 1,2 \& Joaquim M Oliveira ${ }^{*, 1,2}$

13B's Research Group - Biomaterials, Biodegradables \& Biomimetics, University of Minho, Headquarters of the European Institute of Excellence on Tissue Engineering \& Regenerative Medicine, Avepark - Parque de Ciência e Tecnologia, Zona Industrial da Gandra, 4805-017 Barco GMR, Portugal ${ }^{2}$ ICVS/3B's - PT Government Associated Laboratory, Braga/Guimarães, Portugal ${ }^{3}$ Life \& Health Sciences Research Institute (ICVS), School of Health Sciences, Campus de Gualtar, University of Minho, 4710-057 Braga, Portugal

*Author for correspondence: miguel.oliveira@dep.uminho.pt 
gression. However, useful 2D culture conditions do not satisfyingly emulate the in vivo scenario, and new information on cancer cell behavior could be exposed under a more relevant physiological environment [10].

Microfluidic technologies have been proposed as improved in vitro tools, once they can be projected to display complex structures within dynamic environments [11]. A microfluidic device, such as Vena8 biochip, is able to realize functions that are not easily imaginable in conventional 2D biological analysis, such as highly parallel, sophisticated high-throughput analysis and single-cell analysis, in terms of morphology, secretome and the influence of growth factors in a well-defined manner that could be beneficial in cancer research [12,13]. Its microfluidic channels on a micrometer and a submicrometer scale are made to mimic human capillaries and allow controlling the flow forces, the mixture of solutions, and the supply of nutrients and biochemical agents in gradients. Moreover, we hypothesized that this model with particular in vivo like features, such as the presence of shear stress, flow and confinement, will shed light on what happens when NPs are injected in vivo and disclose different interactions from those observed in traditional 2D in vitro assays. Other advantage of microfluidics is the inherent miniaturization with a reduction in cell density and amount of material needed for an experiment, which can increase efficiency when working with primary cells, while testing different concentrations of extracts or drugs can be performed simultaneously $[14,15]$. In fact, the combination of microfluidics with tissue engineering to study cancer has been recently reported with very promising results in angiogenesis and metastasis $[16,17])$. These two mechanisms are essential to understand the complex development of cancer $[18,19]$, by providing new data on crosstalk among several cell types.

The association of NP tracking systems with microfluidics holds great promise as an accurate platform for the in vitro validation of new therapies and, consequently, expediting the translation of those therapies into the clinic. In fact, a major problem that has been hampering this translation is the lack of proper in vitro models capable of emulating the in vivo environment, including all the barriers naturally present, such as the blood flow and the interactions with the endothelium and with cells, which are not usually taken into consideration, and the absence of fluorescent-labeled drug delivery systems that prevent the monitoring of therapy efficiency [6,20,21]. Additionally, little is known about NPs' effect when submitted to a physiologically relevant environment similar to the one that cells are surrounded of, further highlighting limitations of the conventional 2D culture conditions. In the work of Fede et al., it is possible to observe the effect of directional flow, as observed in blood vessels, in the cellular uptake of gold NPs, and their noncytotoxicity as compared with cells cultured under static conditions [22].

To address the aforementioned problems, we hypothesized that the use of labeled NPs together with a microfluidic platform is suitable for cancer cell and drug delivery system tracking in real time, which better mimics the in vivo microenvironment than traditional static cultures. This platform works as a transitional model for the assessment of dynamic NP internalization and cancer cell tracking, which will be useful in subsequent studies with $3 \mathrm{D}$ models. The labeled NPs were achieved by grafting the fluorescent label probe fluorescein-5(6)-isothiocyanate (FITC) to carboxymethylchitosan/poly(amidoamine) (CMCht/PAMAM) dendrimer NPs. It is noteworthy that dendrimer NPs can be easily labeled with different fluorochromes, depending on the need for combining different co-stainings. In this work, surfacemodified dendrimers were used due to its remarkable physicochemical and biological properties, and have great potential to be used in fundamental cell biology $[23,24,25]$. Moreover, since the biological properties of poly(amidoamine) (PAMAM) dendrimers can be tuned with respect to their terminal functionality, it is important to investigate the biocompatibility of any new classes of derivatives of PAMAM dendrimers proposed for biological applications.

The modified NPs were characterized with several physicochemical techniques, such as dynamic light scattering (DLS), proton NMR ( $\left.\mathrm{H}^{1} \mathrm{NMR}\right)$, transmission electron microcopy (TEM), atomic force microscopy (AFM) and differential scanning calorimetry (DSC). Cytotoxicity was screened using three different human cancer cell lines: U87MG (glioblastoma); HeLa (cervical cancer) and HCT-116 (colon cancer) by means of performing a tetrazolium reduction (MTS) assay. Proliferation studies were carried out using a DNA quantification assay. Cancer cell lines were exposed to different concentrations of CMCht/ PAMAM dendrimer NPs over a period of 3 days in conventional 2D standard conditions. After finding the highest noncytotoxic concentration, the internalization efficiency was assessed, both qualitatively and quantitatively (using fluorescence microscopy and flow cytometry, respectively), in static 2D cultures and dynamic conditions using Vena8 biochips.

\section{Materials \& methods}

Synthesis of the CMCht/PAMAM dendrimer NPs CMCht with a degree of deacetylation of $80 \%$ and degree of substitution of $47 \%$ was synthesized by a chemical modification route of chitin (Sigma, Darmstadt, Germany) as described by Chen and Park [26]. 
Starburst PAMAM carboxylic-acid-terminated dendrimers, hereafter designated as PAMAM-CT (generation $1.5,20 \%(\mathrm{w} / \mathrm{v})$ methanolic solution) with an ethylenediamine core were purchased (Sigma-Aldrich). CMCht/PAMAM dendrimer NPs were prepared in a step-wise manner as follows: increase the generation of the PAMAM-CT (G 1.5), obtain a PAMAM methyl-ester-terminated dendrimer, react PAMAM and CMCht (the reaction occurs by a condensation reaction between the methyl ester and amine groups), and convert methyl ester groups that do not react into carboxylic groups in the CMCht/PAMAM dendrimer, followed by precipitation. First, the increase of the dendrimers' generation was carried out. For that, an appropriate volume of PAMAM-CT (G 1.5) in methanol was transferred to a volumetric flask and the solvent evaporated off under nitrogen gas, and the traces dried under vacuum in order to completely remove the methanol. The starting compound was re-dissolved in ultrapure water to give a final concentration of $10 \mathrm{mg} \mathrm{ml}^{-1}$ and the $\mathrm{pH}$ was adjusted to 6.5 with dilute hydrochloric acid solution (Riedel de-Haen, Schwerte, Germany). 1-Ethyl(3-dimethylaminopropyl)carbodiimide hydrochloride (EDC, Fluka, Darmstadt, Germany) was then added to the solution at a molar ratio sufficient to modify the carboxylate residue of the dendrimers, and the solution was kept under agitation for $30 \mathrm{~min}$ at room temperature. Ethylenediamine (Sigma, Germany) was added to the solution at a molar ratio equal to that of EDC and left to react for at least $4 \mathrm{~h}$. After this period, the excess of EDC was removed by dialysis (cellulose tubing, benzoylated for separating compounds with a molecular weight of $\leq 1200$, Sigma, Germany). The compound was used without purification in the next step. After preparing the PAMAM-amine terminated compound, an exhaustive alkylation of the primary amines (Michael addition) was performed. An appropriate volume of the PAMAM-amine terminated compound was mixed with methanol (Sigma, Germany) and methyl methacrylate). The solution was kept under agitation in a water bath for $24 \mathrm{~h}$ at $50^{\circ} \mathrm{C}$, to obtain the PAMAM-methyl ester. The CMCht in ultrapure water was mixed with the PAMAM-methyl ester dendrimer, which was previously dissolved in a 20/80 water/methanol (v/v) solution. The final solution was diluted by adding methanol and kept under agitation for $72 \mathrm{~h}$. After this period, CMCht/PAMAM dendrimers with carboxylic-terminated groups were obtained as described elsewhere [27]. CMCht/PAMAM dendrimer NPs were then precipitated after addition of an appropriate volume of saturated $\mathrm{Na}_{2} \mathrm{CO}_{3}$ (Aldrich, Germany) solution and cold acetone (Pronalab, Tlalnepantla, Portugal). Precipitates were collected by filtration and dispersed in ultrapure water for dialysis over a period of $48 \mathrm{~h}$. CMCht/PAMAM dendrimer NPs were obtained by freezing the solution at $80^{\circ} \mathrm{C}$ and freeze-drying (Telstar-Cryodos-80, Terrassa, Portugal) up to 7 days to completely remove the solvent. It is worth noting that the CMCht/PAMAM dendrimer NPs are water soluble at physiological $\mathrm{pH}$.

\section{Labeling of CMCht/PAMAM dendrimer NPs with FITC}

The conjugates of CMCht/PAMAM-FITC were obtained by covalently bonding the amine group of CMCht and the isothiocyanate group of FITC $(10 \mathrm{mg}$ $\mathrm{ml}^{-1}$ FITC (Sigma, Germany) in anhydrous DMSO (Norconcessus, Ermesinde, Portugal) creating a thiourea bond. First, a $10 \mathrm{mg} \mathrm{ml}^{-1}$ CMCht/PAMAM dendrimer NP solution was prepared in a carbonatebicarbonate coupled buffer of $\mathrm{pH}$ 9.2. Then, a solution of FITC/DMSO was added under agitation and kept in the dark at $4^{\circ} \mathrm{C}$ for $8 \mathrm{~h}$. At this moment, the FITC-labeled CMCht/PAMAM dendrimer NP solution was dialyzed against ultrapure water in order to remove unlinked FITC for $24 \mathrm{~h}$ and filtered (pore size $<220 \mathrm{~nm}$ ) in sterile and dark conditions. The final product was obtained after freeze-drying.

\section{Characterization of the CMCht/PAMAM dendrimer NPs}

Transmission electron microscope

The morphology was investigated by TEM (Philips CM-12, FEI Company, The Netherlands, equipped with a MEGA VIEW-II DOCU camera and Image Software Analyzer SIS NT DOCU). For that, the NPs were stained with $2 \%$ of phosphotungstic acid and placed on copper grids for observation.

\section{Atomic force microscopy}

The morphology of the NPs was also investigated using AFM. First, the freeze-dried CMCht/PAMAM dendrimer NPs were dispersed in ultrapure water to obtain a solution with final concentration of $1 \mathrm{mg} \mathrm{ml}^{-1}$ and then one drop was placed over a $9.9 \mathrm{~mm}$ mica disc (Agar Scientific, Essex, England) and blown dried with nitrogen gas for subsequent characterization. Then, the samples were analyzed using the Tapping Mode ${ }^{\mathrm{TM}}$ with a MultiMode AFM connected to a NanoScope III controller, both from Veeco (NY USA), with noncontact silicon nanoprobes (ca. $300 \mathrm{kHz}$ ) from Nanosensors, Switzerland. All images were plane-fitted using the third-degree-flatten procedure included in the NanoScope software version $4.43 \mathrm{r} 8$. The morphometric analysis was performed using the same software.

\section{Dynamic light scattering \\ $\zeta$ potential and particle size of the CMCht/PAMAM dendrimer NPs were measured in a particle size ana-}


lyzer (Zetasizer Nano ZS, Malvern Instruments, Malvern, UK). Particle size analyses were performed by DLS, in an aqueous solution with low concentration of NPs and using disposable sizing cuvettes. Electrophoretic determinations of $\zeta$ potential were investigated using the universal 'dip' cell $\mathrm{pH} 7.4$ in phosphatebuffered saline (PBS) solution. $\zeta$ potential was also investigated in water.

\section{NMR spectroscopy}

In this work, for the determination of CMCht/ PAMAM dendrimer NPs' structure, $\mathrm{H}^{1} \mathrm{NMR}$ analyses were used. For this purpose, NPs were dissolved in deuterated water $\left(\mathrm{D}_{2} \mathrm{O}\right)$. Then, the NMR spectra were obtained with a Mercury- $400 \mathrm{BB}$ operating at a frequency of $399.9 \mathrm{MHz}$ at $50^{\circ} \mathrm{C}$. The $1 \mathrm{D} 1 \mathrm{H}$ spectra were acquired using a $45^{\circ}$ pulse, a spectral width of $6.3 \mathrm{kHz}$ and an acquisition time of $2.001 \mathrm{~s}$.

\section{Differential scanning calorimetry}

DSC was performed to study the thermal stability and changes in crystallinity over a range of temperatures. A known mass of powder was placed in an aluminum pan and a lid was crimped onto the pan. The pan was then placed in the sample cell of a DSC module. The temperature of the DSC module was equilibrated at $35^{\circ} \mathrm{C}$ and then increased at a rate of $10^{\circ} \mathrm{C} \mathrm{min}^{-1}$ under a $\mathrm{N}_{2}$ gas purge until the material began to degrade. The temperatures were obtained for each peak in the resulting curve and provided indications of temperature stability and phase transitions.

\section{In vitro studies under static conditions Cell culture}

Three cell lines were used: U87MG cells (human glioblastoma cell line), HeLa cells (human cervical cancer cell line) and HCT-116 cells (human colon cancer cell line) were originally obtained from the American Collection of Cell Cultures (ATCC, USA). Cells were continuously grown in DMEM (Gibco, MD, USA; Invitrogen, CA, USA) supplemented with $10 \%$ fetal bovine serum and $1 \%$ penicillin and streptomycin under standard conditions $\left(37^{\circ} \mathrm{C}\right.$ in a humidified atmosphere containing $\left.5 \% \mathrm{CO}_{2}\right)$. Subcultures of cells were performed when confluence reached values of approximately $90 \%$. Then, cells were plated at an initial density of $2 \times 10^{4}$ cells well- $^{-1}$ in 24-well plates and exposed to three concentrations of CMCht/PAMAM dendrimer NPs (0.1, 0.5 and $\left.1 \mathrm{mg} \mathrm{ml}^{-1}\right)$ for short-term exposures comprised between 1 and 3 days.

\section{Cell viability}

Forthestudiedcelltypes(HeLa,U87MGandHCT-116), cell viability was assessed by the MTS [3-(4,5-dimeth- ylthiazol-2-yl)-5-(3-carboxymethoxyphenyl)-2(4-sulfophenyl)-2H-tetrazolium] test (VWR, Portugal). At each time point, cell culture medium was replaced by culture medium containing MTS in a 5:1 ratio and incubated for $3 \mathrm{~h}$. Then, $100 \mu \mathrm{l}$ of solution from each well was transferred to 96-well plates, and the optical density was determined at $490 \mathrm{~nm}$. Cultures that were not exposed to the CMCht/PAMAM dendrimer NPs were used as controls.

\section{DNA quantification}

To assess the effect of CMCht/PAMAM dendrimer NPs on cancer cells, the total amount of DNA was measured using the fluorimetric double-stranded DNA (dsDNA) quantification kit (Quant-iT TM PicoGreen ${ }^{\circledR}$ dsDNA Assay Kit, Molecular Probes). HeLa, U87MG and HCT-116 cancer cells were washed with sterile PBS and were lysed with $1 \mathrm{ml}$ of ultrapure water in each well. The cellular suspensions were transferred into microtubes and incubated in a water bath at $37^{\circ} \mathrm{C}$ for $1 \mathrm{~h}$, then stored at $-80^{\circ} \mathrm{C}$ for further analysis. DNA standards were prepared with concentrations varying between 0 and $2 \mu \mathrm{g} \mathrm{ml}^{-1}$. Next, $28.7 \mu \mathrm{l}$ of sample or standard, $71.3 \mu \mathrm{l}$ of PicoGreen solution and $100 \mu \mathrm{l}$ of Tris-HCl-EDTA buffer were mixed in each well of an opaque 96-well plate (Alfagene, Carcavelos, Portugal) and were incubated in the dark for $10 \mathrm{~min}$. After that, fluorescence was measured using an excitation wavelength of $485 \mathrm{~nm}$ and an emission wavelength of $528 \mathrm{~nm}$. A DNA standard curve was prepared with concentrations varying between 0 and $2 \mu \mathrm{g} \mathrm{ml}^{-1}$ and sample DNA values were read off from the standard graph.

\section{In vitro studies under a microfluidic platform} Vena8 biochips

The Vena8 ${ }^{\mathrm{TM}}$ biochip from Cellix ${ }^{\circledR}$ (Dublin, Ireland) is constitute by eight channels with $120 \mu \mathrm{m}$ of height, $800 \mu \mathrm{m}$ of width and $2.8 \mathrm{~cm}$ of length. Each channel is connected to two microwells (one in each end) where a microfluidic recirculating pump controlled by an iPod Touch (Kima ${ }^{\mathrm{TM}}$ pump) is connected. The sample volume of each channel was $10 \mu \mathrm{l}$. The chip was fabricated in optically clear acrylic with a substrate thickness of $500 \mu \mathrm{m}$, enabling the observation of cells using bright field, phase-contrast imaging and fluorescence microscopy.

\section{Cell culture}

A semiautomated microfluidic platform, Vena8 biochip with a glass coverslip (Tebu-Bio, Portugal), was used to mimic physiological flow conditions. Each biochip channel was coated with fibronectin (Sigma, Germany) and then placed in a humidified sterile 
Petri dish, incubated at $37^{\circ} \mathrm{C}$ for $1.5 \mathrm{~h}$. After the incubation period, 15,000 cells (HeLa, U87MG or HCT-116) were gently added into each microchannel and kept in a sterile Petri dish in the incubator for $2 \mathrm{~h}$ to allow cell adhesion. To prevent drying, after the initial $30 \mathrm{~min}$ of incubation, complete medium DMEM was added to the channels. After $3 \mathrm{~h}$, cells were exposed to $0.5 \mathrm{mg} \mathrm{ml}^{-1}$ of CMCht/ PAMAM dendrimer NPs for short-term exposures comprised between 1 and 3 days. Medium was added three-times per day.

\section{Cell viability}

Cells were seeded at an initial density of 15,000 cells channel $^{-1}$ (day 1 time point) and 10,000 (day 3 time point) and exposed to $0.5 \mathrm{mg} \mathrm{ml}^{-1}$ of CMCht/PAMAM dendrimer NPs for short-term exposures comprised between 1 and 3 days. The effect of CMCht/PAMAM NPs on cell viability was tested with medium renewal three-times per day. Cells cultured in complete culture medium were used as controls.

To test cell viability using the MTS method, cells from each channel were detached using Tryple Express (Alfagene, Portugal). Cells were aspirated and collected in a $1.5-\mathrm{ml}$ tube. After centrifugation $(5 \mathrm{~min}$, $1500 \times g$ r.p.m.) cells were incubated with culture medium containing MTS in a 5:1 ratio and analyzed as aforementioned for $2 \mathrm{D}$ standard cell cultures.

\section{DNA quantification}

To assess the effect of CMCht/PAMAM dendrimer NPs on cancer cells in the microfluidic chip, the total amount of DNA was measured using Quant-iT ${ }^{\mathrm{TM}}$ PicoGreen ${ }^{\circledR}$ dsDNA Assay Kit. HeLa, U87MG and HCT116 cancer cells were plated at a density of 15,000 cells microchannel ${ }^{-1}$ and incubated with CMCht/PAMAM dendrimer NPs at a concentration of $0.5 \mathrm{mg} \mathrm{ml}^{-1}$ up to 1-3 days. Cells cultured in complete culture medium were used as controls. After the incubation, cancer cells from each channel were washed with sterile PBS and detached using Tryple Express Enzyme (Alfagene, Portugal). Cells were aspirated and collected in a $1.5 \mathrm{ml}$ tube and lysed with $1 \mathrm{ml}$ of ultrapure water. The cellular suspensions were incubated in a water bath at $37^{\circ} \mathrm{C}$ for $1 \mathrm{~h}$, then stored at $-80^{\circ} \mathrm{C}$ for further analysis as described previously.

\section{Assessment of internalization efficiency in 2D standard cultures \& using a microfluidic platform \\ Fluorescence microscopy}

To assess the internalization and possible cell morphological changes at each time point, a cell suspension was prepared and seeded on tissue culture polystyrene coverslips (Sarstedt Inc., USA) in 24-well plates $(2 \times$ $10^{4}$ cells well- $^{-1}$ ) and cultured with $0.5 \mathrm{mg} \mathrm{ml}^{-1}$ FITClabeled CMCht/PAMAM dendrimer NPs, in standard culture conditions for 1 and 3 days. Then cells were fixed with $4 \%$ formalin (Sigma, Germany) and stained for F-actin filaments of the cytoskeleton and nuclei with Texas Red-X phalloidin (Molecular Probes, Invitrogen, USA) and with 4,6-diamidino-2-phenylindole, dilactate (DAPI blue, Molecular Probes), respectively, following supplier's protocol. For dynamic cultures, cells were cultured as described previously in the microfluidic platform and were fixed with $10 \mu \mathrm{l}$ channel $^{-1}$ of $4 \%$ formalin (Sigma, Germany) for $10 \mathrm{~min}$. Then, $10 \mu$ channel $^{-1}$ of DAPI and Texas Red-X phalloidin were perfused into the microchannels to stain the nuclei and the cytoskeleton F-actin filaments, respectively. Finally, cells were observed under the fluorescence microscope (AxioImager Z1, Zeiss Inc., Oberkochen, Germany).

\section{Flow cytometry analysis}

To quantify the internalization of FITC-labeled CMCht/PAMAM dendrimer NPs, flow cytometry analysis was performed. In static conditions, cancer cells were cultured in the presence of $0.5 \mathrm{mg} \mathrm{ml}^{-1}$ FITC-labeled CMCht/PAMAM dendrimer NPs in a 6 -well plate $\left(2 \times 10^{5}\right.$ cells well $\left.^{-1}\right)$. Cells cultured in complete culture medium were used as controls. Cells were released from a substratum and a cell strainer was used to avoid cell clusters. Afterward, $0.5 \mathrm{ml}$ of DMEM complete medium was added to each well and samples transferred to cytometry tubes.

In dynamic conditions, cancer cells were cultured in the presence of $0.5 \mathrm{mg} \mathrm{ml}^{-1}$ FITC-labeled CMCht/ PAMAM dendrimer NPs in the microfluidic chips. Cells cultured in complete culture medium were used as controls. FACS analysis was carried out to perform quantitative analysis on the internalization efficiency as well as cell viability, as follows: each channel was washed with PBS. Then, PBS was aspirated, and cells from each channel were detached using $10 \mu$ l of Tryple Express and collected in an FACS tube. After centrifugation at $1500 \times g$ r.p.m. for $5 \mathrm{~min}$, cells were resuspended in $800 \mu \mathrm{l}$ of a $2 \%$ fetal bovine serum in PBS solution. Afterward, $5 \mu \mathrm{l}$ of 7-Aminoactinomycin D (7-AAD; Taper group, Portugal) was added to each sample for determining the number of dead cells. After this step, cells were loaded in FACSCalibur flow cytometer (BD Biosciences Immunocytometry Systems, CA, USA). Calibrate beads three-color kit (BD CaliBRITETM beads, CA, USA) was used to adjust the equipment instrument settings before samples are run on the flow cytometer. Finally, data were treated using the Flowing Software 2. 


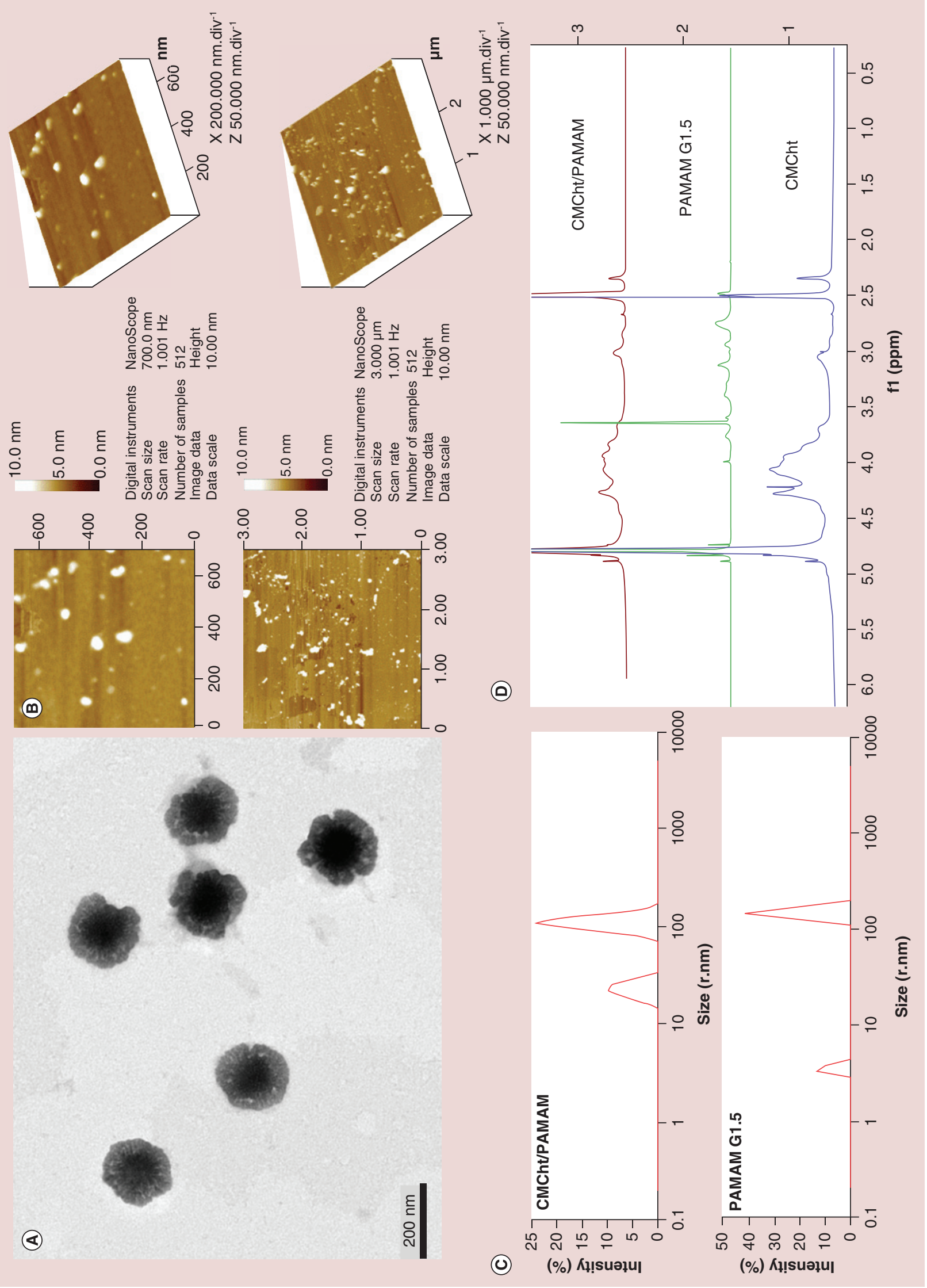




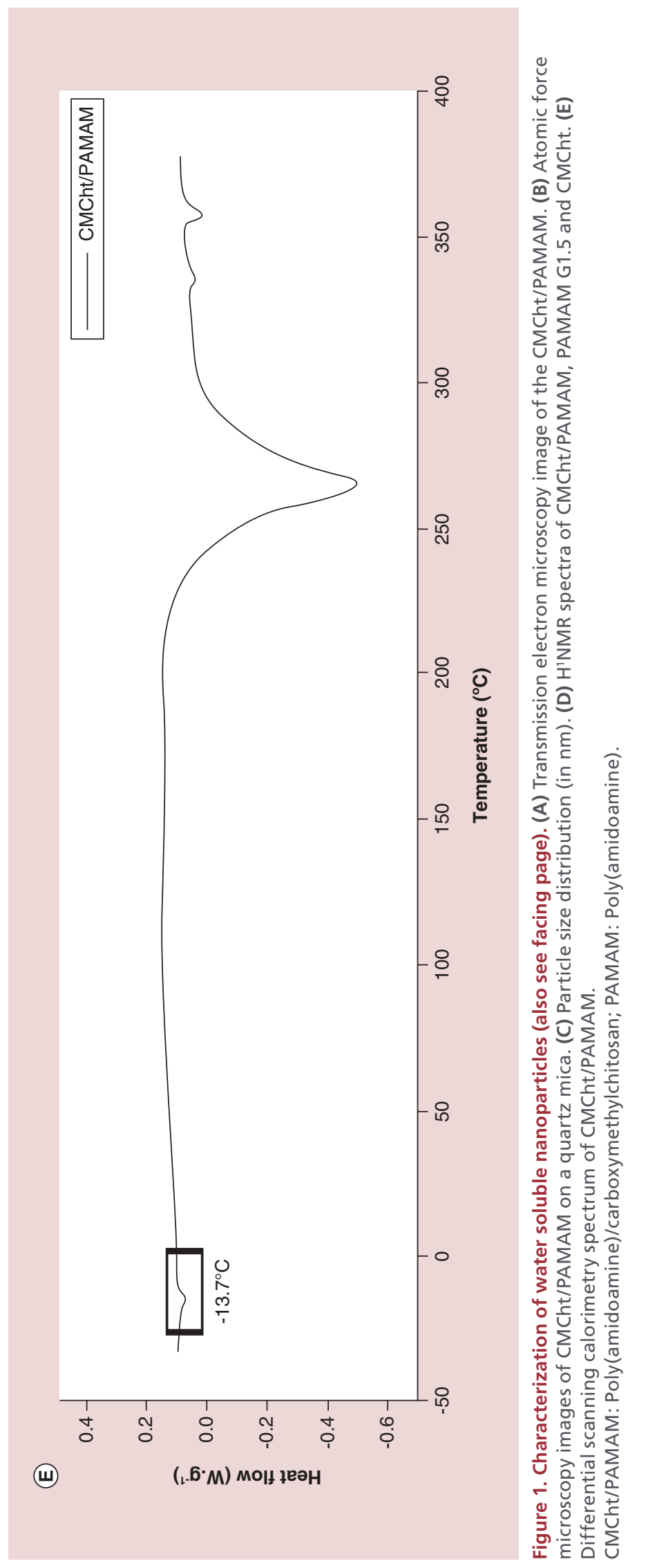




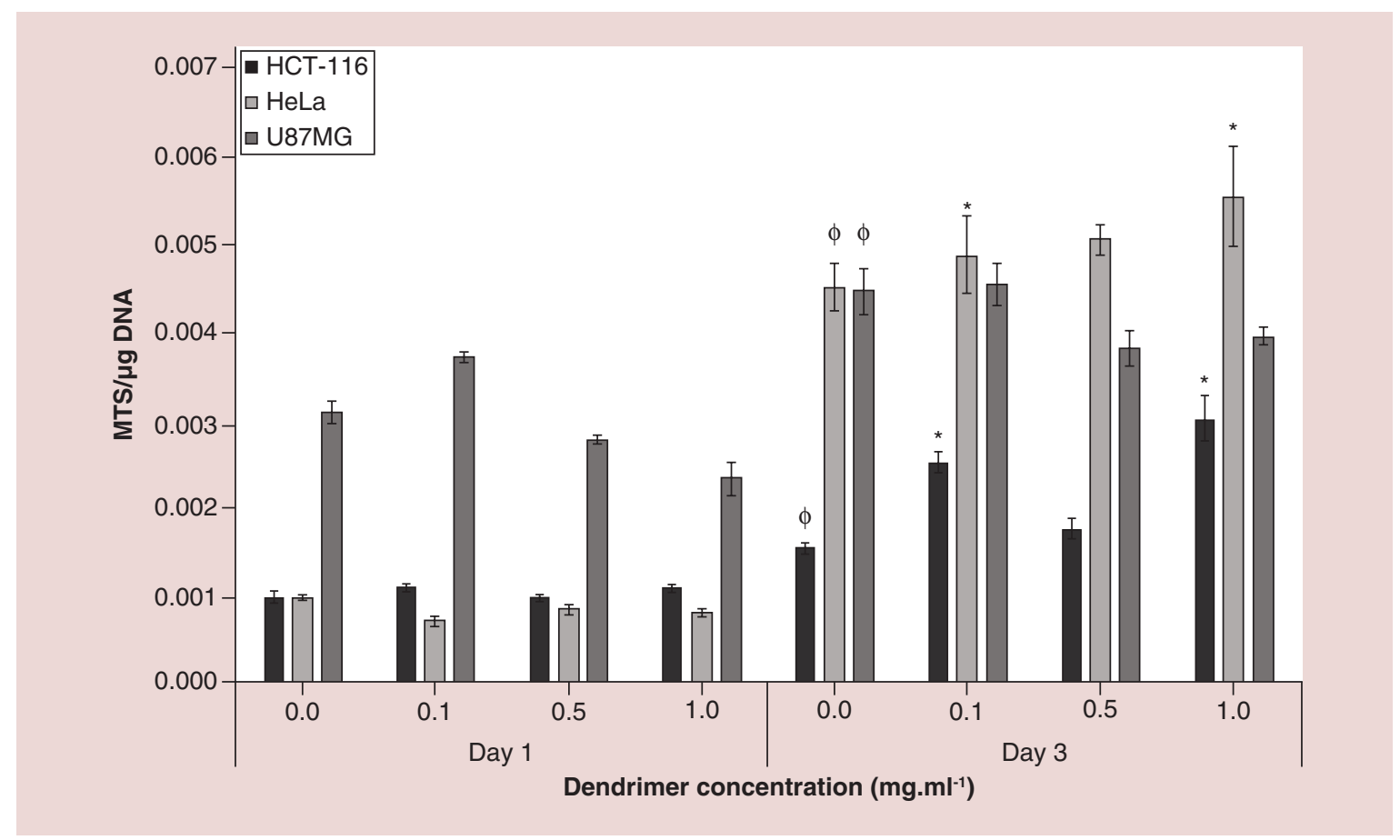

Figure 2. Normalization of MTS results by DNA results of HCT-116, HeLa and U87MG human cancer cell lines in static conditions in the presence of poly(amidoamine)/carboxymethylchitosan dendrimer nanoparticles. Assays were conducted to assess the cytotoxicity effect of nanoparticles on cell viability at concentrations of $0.1,0.5$ and $1 \mathrm{mg} \mathrm{ml}^{-1}$ at time points of 1 and 3 days.

*Significant differences when comparing the different concentrations with control $\left(0 \mathrm{mg} \mathrm{ml}^{-1}\right)$ at each time point. ${ }^{\Phi}$ Significant differences when comparing controls from day 3 with day 1 to determine cell proliferation).

\section{Statistical analysis}

Statistical evaluation was performed using GraphPad Prism 5.0 software version 5.0a. The nonparametric Mann-Whitney test was used to compare two groups and the Tukey's test was used to compare results of dendrimers' cytotoxicity after normalization. Statistical significance was defined as $\mathrm{p}<0.05$ for a 95\% CI. All measurements were taken in triplicate and the data are shown as mean \pm standard deviation.

\section{Results}

\section{Characterization of the CMCht/PAMAM dendrimer NPs}

In order to gain deeper knowledge on the CMCht/ PAMAM dendrimer NPs' physicochemical properties, both TEM and AFM studies were performed. Their architecture determined in dry conditions is depicted in Figure $1 A \& B$. From Figure $1 A$, it is clearly visible the monodispersed character of these particles, as well as the polymer coating around PAMAM's core and a clear dendron-like morphology, which was further confirmed by AFM analysis as shown in Figure 1B. In fact, it is possible to observe the 3D AFM image of the CMCht/PAMAM dendrimer NPs, which noticeably shows the consistency of these molecules, in other words, nanosphere-like shape. By assessing the particle distribution using DLS, it revealed that the CMCht/ PAMAM dendrimer NPs have an average size of $50 \mathrm{~nm}$ (Figure 1C). After the synthesis of the CMCht/ PAMAM dendrimer NPs, three types of particles were clearly detected, with sizes approximately $6 \pm 1,54 \pm$ 7 and $674 \pm 462 \mathrm{~nm}$. The first graph corresponds to the modified dendrimer NPs with CMCht where two peaks are present, corresponding to single and aggregated NPs, respectively. The second graph corresponds to the unmodified PAMAM dendrimer of generation 1.5 , also with two visible peaks. These correspond to single and aggregated NPs. $\zeta$ potential data show that NPs dispersed in water at neutral $\mathrm{pH}$ present negative charge of $-34.3 \pm 3(\mathrm{mV})$.

Figure 1D shows the $\mathrm{H}^{1} \mathrm{NMR}$ spectrum of the synthesized CMCht/PAMAM dendrimer NPs and its comparison with unmodified PAMAM dendrimer and biocompatible polymer CMCht, revealing a singlet at $2.49 \mathrm{ppm}$ and multiplets from 3.1 to $3.73 \mathrm{ppm}$ and $4.07 \mathrm{ppm}$ associated with the $\mathrm{H}^{2}$ protons, the ring methine protons $\left(\mathrm{H}^{3}, \mathrm{H}^{4}, \mathrm{H}^{5}\right.$ and $\left.\mathrm{H}^{6}\right)$, and protons of $-\mathrm{CH}_{2} \mathrm{COO}-$ groups of the CMCht. Also, peaks at 2.49 and $3.46 \mathrm{ppm}$ appear overlapped as a result of the resonances of the $\mathrm{CH}_{2} \mathrm{COO}$ and $\mathrm{CH}_{2}$ protons of both CMCht and PAMAM. The presence of the peak at ca. $3 \mathrm{ppm}$ and the absence of a peak at $4.3 \mathrm{ppm}$ 
can indicate that the substitutions occurred mainly on the C2 amino group of CMCht. Finally, DSC thermogram analysis to assess thermal stability of the modified dendrimer shown in Figure $1 \mathrm{E}$ reveals a glass transition temperature $(\mathrm{Tg})$ of $-13.7^{\circ} \mathrm{C}$ and a thermal decomposition at $267^{\circ} \mathrm{C}$.

\section{Cell viability/proliferation in static conditions}

Cell viability and proliferation were determined by means of performing MTS and DNA quantification assays (Figure 2). The three chosen cancer cell lines were exposed to a range of dendrimer concentrations over a period of 3 days. Our results indicated no deleterious effects on cell viability in static culture conditions, when comparing the tested and control samples $(\mathrm{p}<0.0001)$. Therefore, the tested conditions were not affected significantly by the presence of CMCht/ PAMAM dendrimer NPs. It is clear that all cancer cell lines proliferate in a significant manner from day 1 to day 3 in the absence of NPs (controls). As depicted in Figure 2, the concentration with less variability, more consistent results (low standard deviations) and more alike to the control group (no statistically significant differences) was $0.5 \mathrm{mg} \mathrm{ml}^{-1}$. These preliminary tests allowed us to screen three types of relevant cancer cell lines with a wide range of concentrations and choose the most adequate one to proceed to comparative studies between static and dynamic conditions of culture, in order to validate a model for real-time tracking. So, from this point onward, all the tests were performed with a dendrimer NP concentration of $0.5 \mathrm{mg} \mathrm{ml}^{-1}$.

\section{Cell viability/proliferation in dynamic conditions}

Figure 3 shows the results of the two tested groups (static and dynamic) at day 1 and day 3 , in the absence or presence of NPs $\left(0.5 \mathrm{mg} \mathrm{ml}^{-1}\right)$, for easy comparison. The shown results represent the normalization between the two tests. Regarding the dynamic condition, HCT-116 cells showed greater sensitivity in the presence of NPs, both in day 1 and day 3, which is translated into a decrease of viability. U87MG cells, by its turn, showed this significant difference between the control and NP groups only at day 3 . However, for HeLa cells, no significant differences were observed in dynamic conditions regarding the effect of NPs.

\section{Assessment of NPs cellular uptake in 2D standard cultures \\ Fluorescence microscopy \& flow cytometry analysis}

Figure 4 shows the fluorescence microscopy images obtained after culturing the three cancer cell lines

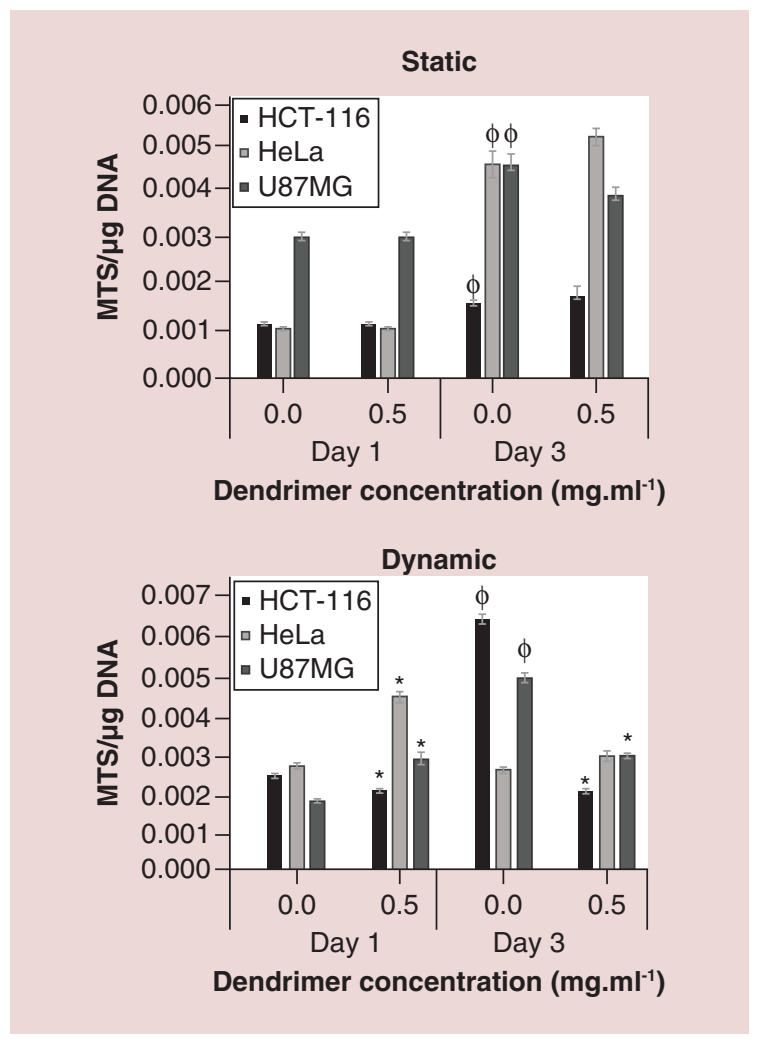

Figure 3. Cytotoxicity of poly(amidoamine)/ carboxymethylchitosan over HCT-116, HeLa and U87MG human cancer cell lines in static and dynamic conditions. Assays were conducted to assess cytotoxicity/viability over the cells at a concentration of $0.5 \mathrm{mg} \mathrm{ml}^{-1}$ at different time points (days 1 and 3) and it in static and dynamic conditions.

*Significant differences when comparing $0.5 \mathrm{mg} \mathrm{ml}^{-1}$ with control $\left(0 \mathrm{mg} \mathrm{ml}^{-1}\right)$ at each time point.

'Significant differences when comparing controls from day 3 with day 1 to determine cell proliferation).

with $0.5 \mathrm{mg} \mathrm{ml}^{-1}$ of FITC-CMCht/PAMAM for 1 and 3 days in static conditions. As can be observed, all cancer cells were able to internalize the fluorescent labeled NPs. NPs are dispersed in the cytoplasm but especially around the nucleus (stained with DAPI). Also, it is clear that the internalization rate tended to increase with time. The microscopic observation of cells showed no relevant cell morphological changes, which corroborate the lack of cytotoxicity.

Quantitative analysis of NPs' uptake at the cellular level was performed using the flow cytometry analysis. Table 1 shows the percentage of internalization of FITC-labeled CMCht/PAMAM dendrimer NPs by each cell line under static conditions, as well as the percentage of live cells obtained by staining with 7-AAD, determined by flow cytometry.

Flow cytometry results of cancer cell lines cultured in the presence of FITC-labeled CMCht/PAMAM dendrimer NPs showed that HeLa cancer cells contin- 


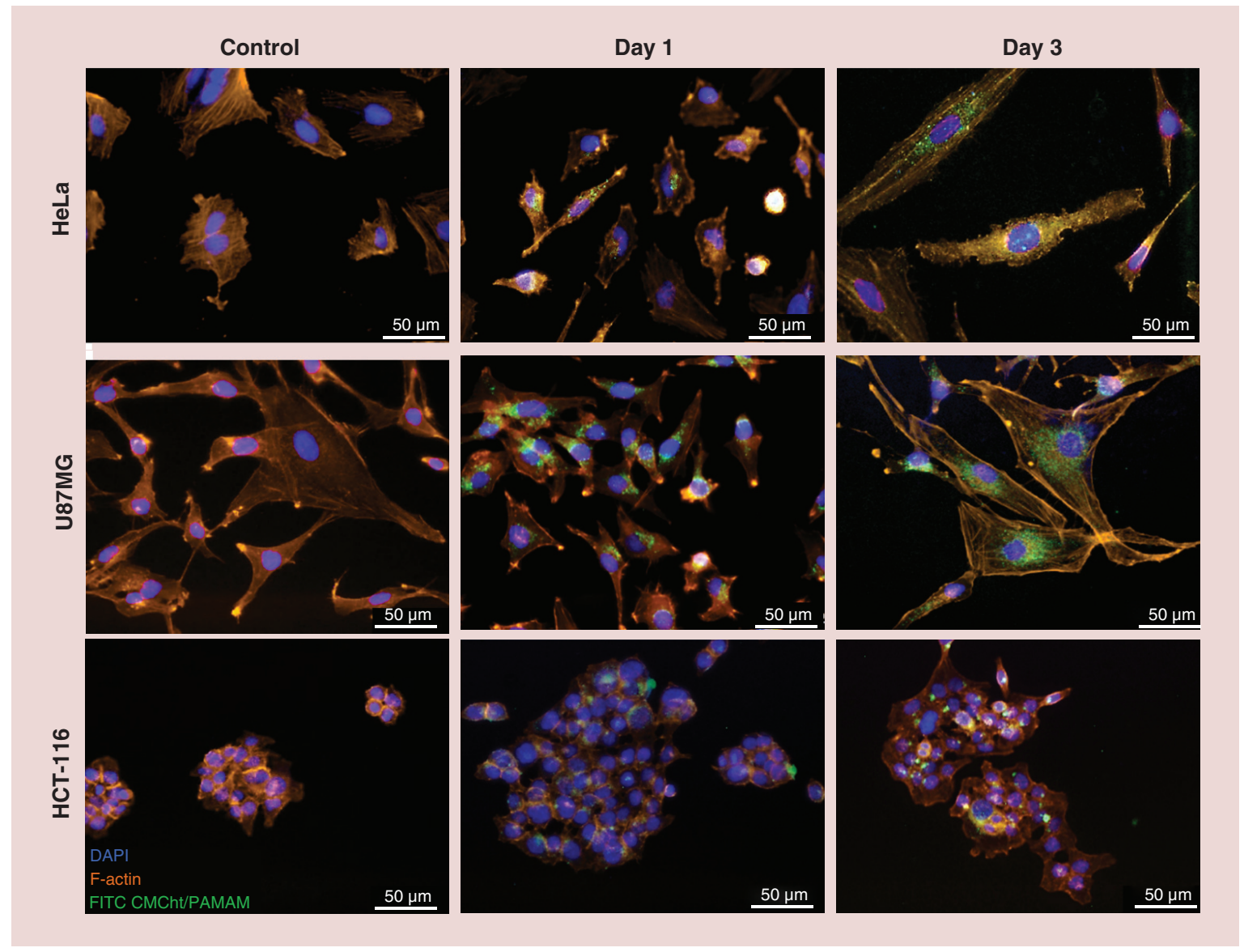

Figure 4. Fluorescent microscope images of fluorescein-5(6)-isothiocyanate-labeled poly(amidoamine)/ carboxymethylchitosan dendrimer nanoaparticles (green) internalization in cancer cells labeled with 4,6-diamidino-2-phenylindole, dilactate (nuclei) and phalloidin (F-actin, cytoskeleton) after 1 and 3 days in direct contact with dendrimer nanoparticles in static conditions.

ued to internalize the NPs along time, starting with an internalization percentage of $87 \%$ by day 1 , and increasing to $99 \%$ by day 3 (higher fluorescent signals along time). By its turn, U87MG and HCT-116 internalization rates were constant and reached the maximum peak, as almost $100 \%$ of cells showed internalized NPs only after $24 \mathrm{~h}$. Regarding cell viability in static conditions, it is possible to observe that cells remain viable in the presence of dendrimer NPs (percentage of live cells on day 1 is very similar to day 3) and no relevant cytotoxic effects are noted when compared with controls (see Table 1).

Table 1. FACS data of the percentage of internalization of fluorescein-5(6)-isothiocyanate-labeled poly(amidoamine)/carboxymethylchitosan dendrimer nanoparticles and the percentage of live cells (stained with 7AAD), from day 1 to day 3 under static conditions.

\begin{tabular}{|c|c|c|c|c|}
\hline Culture conditions & & ation (\%) & & Ills (\%) \\
\hline Static & Day 1 & Day 3 & Day 1 & Day 3 \\
\hline HeLa (NP) & 87 & 99 & 96 & 97 \\
\hline HeLa (control) & 0 & 0 & 99 & 99 \\
\hline U87MG (NP) & 98 & 98 & 97 & 95 \\
\hline U87MG (control) & 0 & 0 & 99 & 99 \\
\hline HCT-116 (NP) & 100 & 99 & 97 & 97 \\
\hline HCT-116 (control) & 0 & 0 & 99 & 100 \\
\hline
\end{tabular}


Table 2. FACS data of the percentage of internalization of fluorescein-5(6)-isothiocyanate-labeled poly(amidoamine)/carboxymethylchitosan dendrimer nanoparticles and the percentage of live cells (stained with 7AAD), from day 1 to day 3 in dynamic conditions.

\begin{tabular}{|c|c|c|c|c|}
\hline Culture conditions & & zation (\%) & & ells (\%) \\
\hline Dynamic & Day 1 & Day 3 & Day 1 & Day 3 \\
\hline HeLa (NP) & 95 & 100 & 97 & 97 \\
\hline HeLa (control) & 0 & 0 & 100 & 100 \\
\hline U87MG (NP) & 99 & 99 & 95 & 92 \\
\hline U87MG (control) & 0 & 0 & 99 & 98 \\
\hline HCT-116 (NP) & 100 & 99 & 90 & 90 \\
\hline HCT (control) & 0 & 0 & 99 & 99 \\
\hline
\end{tabular}

Assessment of internalization efficiency using a microfluidic platform

Fluorescence microscopy \& flow cytometry analysis Figure 5 represents a panel of images with results obtained after 1 and 3 days of culture in the presence of FITC-CMCht/PAMAM at a concentration of $0.5 \mathrm{mg} \mathrm{ml}^{-1}$, in dynamic culturing conditions. As can be observed, all cancer cells were able to internalize the fluorescent-labeled NPs when cultured in the microfluidic system.

Flow cytometry studies on cells cultured in dynamic conditions reveal similar results to static conditions when it comes to NPs' internalization performance. Cells are able to internalize NPs almost at the maximum rate by $24 \mathrm{~h}$ after the beginning of the experiment (Table 2). Concerning cell viability, it is possible to observe differences between the absence and the presence of NPs. In fact, all cancer cells show decreased viability in the presence of NPs. Special emphasis in HCT-116 with a percentage of live cells of $90 \%$ when compared with the respective control (99\%), followed by U87MG with $95 \%$ against $99 \%$ of the control, and finally HeLa cells with a percentage of $97 \%$ in the presence of NPs and $100 \%$ in the control. It is worth noting that the viability in relation to control was kept when analyzing day 3 .

\section{Discussion}

Although the cancer research field has been evolving along the years, there is still missing a proper tool to track cells and therapy efficiency in real time, allowing the interpretation of their interaction and expediting its translation into the clinics. Cell movement, location and quantification studies require specialized probes that are noncytotoxic and are available in a range of fluorescent colors to match instrument lasers and filters, and to accommodate co-staining with antibodies or other cell analysis probes.
In light of this, the main goal of this work was aimed at developing a new platform composed of fluorescent-labeled NPs associated with a microfluidic device, which may be useful for the validation of new theranostic approaches. To accomplish this, we investigated the interactions between a new class of labeled NPs, developed previously by our group [28], and several cancer cell lines, both in standard 2D static culture systems and in a dynamic microfluidic chip.

The in vitro studies demonstrated that cells remain viable in both culturing conditions. However, cell cultures in the dynamic systems displayed higher sensitivity to NPs, disclosing the real importance of a more physiologically relevant model for the development of new cancer therapies, otherwise, no differences in cell response should be found. Additionally, as the developed NPs show internalization rates near to 100\% (all the cells in culture have internalized fluorescent labeled NPs) after $24 \mathrm{~h}$ in culture, they enable real-time monitoring of drug delivery systems efficiency accelerating its translation into clinics.

Recently, our group has proposed a strategy to chemically modify PAMAM dendrimer NPs with CMCht in order to achieve water solubility and low cytotoxicity, making them ideal for this purpose [28]. The first steps were to synthetize and modify the NPs and to physicochemically characterize them, prior to their use in biological studies. The chosen methods are simple and reliable tools to determine chemical composition, morphological features and surface chemistry, such as TEM, AFM, DLS, $\mathrm{H}^{1} \mathrm{NMR}$ and DSC methods. In this study, the TEM analysis (Figure 1A) clearly revealed a dendron-like morphology with a central core and the added CMCht polymer coating. These data were further confirmed by AFM analysis (Figure 1B) that visibly showed the consistency of these molecules' features, in other words, nanosphere-like shape, which is in agreement with previously described results [28,29]. 


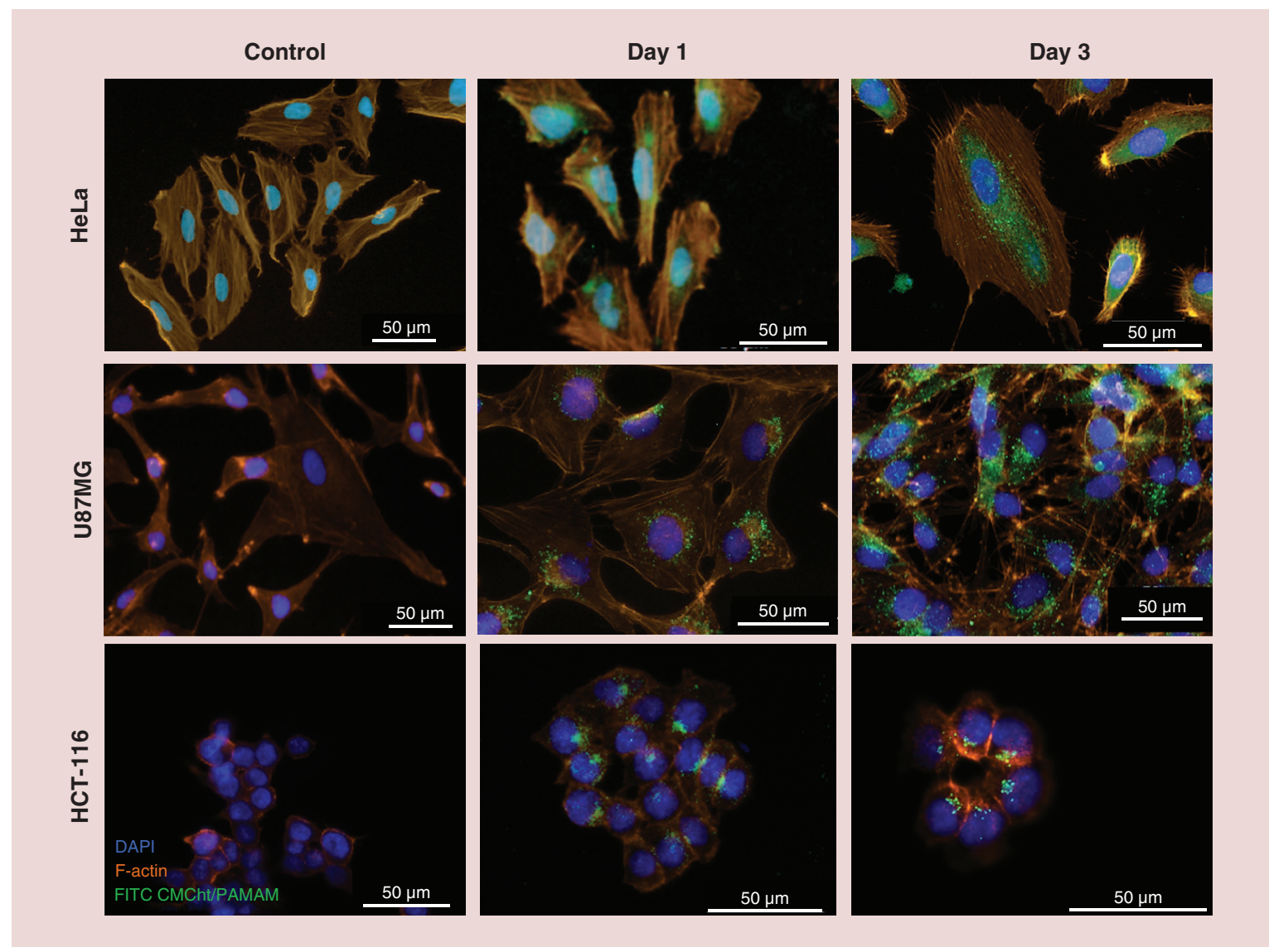

Figure 5. Fluorescent microscope images of fluorescein-5(6)-isothiocyanate-labeled poly(amidoamine)/ carboxymethylchitosan dendrimer nanoparticles (green) internalization in cancer cells labeled with 4,6-diamidino-2-phenylindole, dilactate (nuclei) and phalloidin (F-actin, cytoskeleton) after 24 and $72 \mathrm{~h}$ in direct contact in dynamic conditions.

CMCht/PAMAM dendrimer NPs were also analyzed with DLS. Particle size is one of the most important parameters in drug carriers for intracellular delivery, as well as the surface charge, which was also measured. Three sizes of particles were detected, approximately $6 \pm 1,54 \pm 7$ and $674 \pm 462 \mathrm{~nm}$ (Figure 1C). In the first graph, where the analysis of CMCht/PAMAM dendrimer is depicted, the first peak corresponds to the modified dendrimer and the second to the aggregates. Concerning the second graph, the first peak matches the size of the isolated unmodified PAMAM G1.5 dendrimer NPs and the second to the size of aggregated NPs. The last group, the aggregated NPs, can be explained by interactions between noncovalent free carboxyl groups of CMCht and/or unmodified PAMAM-carboxyl terminal dendrimer and amino groups of other CMCht particles, which may promote the formation of NP aggregates [30]. This is a property involving not only the surface properties of the particles but also their environment, for example, $\mathrm{pH}$, ionic strength and even the type of ions in the suspension. By its turn, it is expected that CMCht has a good $\mathrm{pH}$ and ion sensitivity in aqueous solution due to abundant $-\mathrm{COOH}$ and $-\mathrm{NH}_{2}$ groups.

These results corroborate the theory that the negatively charged carboxymethyl groups in the CMCht/ PAMAM dendrimer NPs are mainly distributed at the surface of the NPs, working as a water-soluble coating, as confirmed by the DLS data.

Regarding the $\mathrm{H}^{1} \mathrm{NMR}$ analysis, the singlet at $2.49 \mathrm{ppm}$ and multiplets from 3.1 to $3.73 \mathrm{ppm}$ and $4.07 \mathrm{ppm}$ are associated with the $\mathrm{H}^{2}$ protons, the ring methine protons $\left(\mathrm{H}^{3}, \mathrm{H}^{4}, \mathrm{H}^{5}\right.$ and $\left.\mathrm{H}^{6}\right)$ and protons of $-\mathrm{CH}_{2} \mathrm{COO}^{-}$groups of the CMCht, respectively $[30,31]$. Also, the presence of peaks from 1.98 to $3.46 \mathrm{ppm}$ is noteworthy because they point the presence of PAMAM dendrimer. These have been attributed to $\mathrm{CH}_{2} \mathrm{COO}, \mathrm{CH}_{2} \mathrm{CO}$ and $\mathrm{CH}_{2} \mathrm{CN}$ groups. The presence of the peak at ca. $3 \mathrm{ppm}$ and the absence of a peak at $4.3 \mathrm{ppm}$ can indicate that the substitutions occurred mainly on the $\mathrm{C} 2$ amino group of CMCht, confirming the modification of the PAMAM dendrimer.

The DSC studies were performed to assess the thermal stability of PAMAM dendrimers modified with 
CMCht. The thermal degradation was observed at $267^{\circ} \mathrm{C}$ indicating that the developed dendrimers are high thermally stable at body temperature. This high value could be due to the presence of hydrogen bonds in the structure of PAMAM, as observed previously [32]. Nevertheless, it is lower than that observed in previous studies made with other generations of PAMAM dendrimers [33]. This variation can be explained by the contribution of CMCht polymer. In fact, it was previously shown that the longer the grafted polymers are, the lower the values of thermal degradation obtained, and consequently the less stable the dendrimer is [34]. Moreover, a thermal glass transition temperature is clear at $-13.7^{\circ} \mathrm{C}$. To the best of our knowledge, this type of characterization has never been done in this specific type of modified dendrimers and therefore could serve as a reference for future works.

Regarding the biological assays, similar to what has been done by Oliveira and co-workers for neurons, glial cells [29], fibroblasts (L929) and rat bone marrow stromal cells [28], the cytotoxic effect of different concentrations of CMCht/PAMAM dendrimer NPs on glioblastoma cancer cells, colon cancer cells and cervical cancer cells, along the time, was the first parameter to be assessed, as a bridge to dynamic experiments. This allowed us to select the higher noncytotoxic concentration to be used in subsequent assays, which was $0.5 \mathrm{mg} \mathrm{ml}^{-1}$. After that, standard 2D culture systems in cell culture TCPS well-plate (static conditions) and cultures inside a microchannel in a microfluidic device (dynamic conditions) were comparatively investigated. The last culture system works as a bridge toward more elaborated 3D models, as it mimics the natural environment that cells and NPs are exposed to, once in systemic circulation in vivo [35], regarding confinement, flow and shear stress. Figure 2 represents the results of the screening under static conditions, which indicates highly metabolically active cells. HCT-116, HeLa and U87MG proliferated well and were viable either in the controls (absence of NPs) or in the presence of NPs at any given concentration. Statistically, it is possible to observe that increasing concentrations of CMCht/PAMAM (0.1, 0.5 and $1 \mathrm{mg} \mathrm{ml}^{-1}$ ) did not affect the viability or proliferation of cancer cell lines. This can be explained by the natural aggressiveness and resistance of cancer cell lines [36] when compared with other cell types as showed in the work of Oliveira et al. [28,30]. Hence, we decided to use the intermediate concentration: $0.5 \mathrm{mg} \mathrm{ml}^{-1}$ as it shows no statistical differences when compared with the controls, and because it could potentially increase the number of NPs inside the cells when compared with the lowest concentration $\left(0.1 \mathrm{mg} \mathrm{ml}^{-1}\right)$.

When static conditions were compared with dynamic conditions (Figure 4), in which cells were exposed to
$0.5 \mathrm{mg} \mathrm{ml}^{-1}$ for the same periods of time, HCT-116 cells showed a clear sensitivity to NPs, especially at day 3, as well as U87MG cells. None of these phenomena were observed in static standard conditions, highlighting the importance of using a system that mimics features of the in vivo environment. Therefore, the main differences between the two culture conditions rely on the fact that NPs show no effect on any of the chosen cancer cell lines at any time point in static conditions. Nevertheless, when the same cells were cultured in a confined and dynamic environment, they showed to be more sensitive. Moreover, we observed that their growth is much greater in static conditions (statistic differences from day 1 to day 3) which can be due to the fact that they proliferate freely in traditional 2D culture conditions, in contrast to what was observed in dynamic conditions due to the limited space available within the microchannels of the microfluidic device. This is why it is also worth noting the short time exposures ( 3 days) used in this work instead of the traditional 14 days' exposure. In fact, microfluidic devices, such as Vena8 chips, are made to speed up and scale down experiments [37].

Qualitative images obtained with fluorescence microscope revealed that either in static and dynamic conditions, HCT-116, U87MG and HeLa cells were able to broadly internalize fluorescence labeled NPs at a very quick rate after 1 day in culture. The normal morphology of the cells (marked by DAPI and phalloidin) suggests healthy proliferation and survival under both conditions (Figures $4 \& 5$ ). It is not clear whether the particles are also located inside the nucleus just by observing the microscope images. Further experiments are required to clarify the fate of these NPs. The same effect has been observed earlier by Oliveira $e t$ al. [28] in L929 and Saos2 cell lines.

These findings were later corroborated by flow cytometry, which was used to quantitatively study the levels of FITC-labeled CMCht/PAMAM dendrimer NPs internalized by cells. Quantitative analysis of NPs' uptake at the cellular level is critical for a realistic evaluation of their effects and to compare possible different behaviors among different cell culture times. FACS analysis was performed to circumvent this limitation since each cell line interacts differently with NPs [38].

Results from Table 1 revealed increasing levels of fluorescence for HeLa cells from day $1(87 \%)$ to day 3 (99\%), in static conditions. By its turn, U87MG and HCT-116 cells' internalization rates were constant and reached the maximum peak, as almost $100 \%$ of cells showed internalized NPs only after 1 day. A similar trend was observed in dynamic conditions (Table 2). Although HeLa cells showed slower internalization rates, as compared with U87MG and HCT-116 cells, 
a higher rate of internalization was observed at day 1 when compared with static conditions $(87 \%$ in static vs $95 \%$ in dynamic), which could influence, for example, the optimization of drug concentration used, showing once again the relevance of using a dynamic system for validation of new therapies. The fact that HeLa cells take more time to internalize NPs in both culture conditions could be related and possibly explain their higher sensitivity. Nevertheless, it is important to point out that almost $100 \%$ of cells were labeled after 1 day, indicating that the developed NPs present great potential as the cell-tracking system.

Additionally, we used flow cytometry to measure the viability levels of cells in both conditions (static vs dynamic) using 7-AAD. 7-AAD appears to be generally excluded from live cells, creating complexes only with free DNA from dead cells, making it an excellent quantitative indicator of cell viability, as it gives fluorescent signal for dead cells only. By quantifying the percentage of live cells, we observed that there were no significant differences between the controls and the presence of $0.5 \mathrm{mg} \mathrm{ml}^{-1}$ of NPs in static studies (Table 1). On the other hand, when seeded and cultured in the microfluidic chips with dynamic flow, cells showed higher sensitivity, displaying higher percentages of dead cells, as depicted in Table 2. It is worth noting that the results obtained by flow cytometry analysis corroborate the results of MTS/DNA tests.

In brief, these findings suggest that standard 2D assays underestimated the effect of CMCht/PAMAM dendrimer NPs, while microfluidic chips, which represent a dynamic setting, unraveled the real cytotoxicity and internalization rates of the labeled NPs [39,40]. This could only be possible due to the combination of dendrimer NPs with fluorescent dye, which allowed real-time monitoring of cells in this new system, envisaging the use for new therapies validation in real time. Despite the interesting data, we envision performing deeper studies to investigate the effect of loading an anticancer drug into the NPs on cancer cell lines in the proposed microfluidic chip.

\section{Conclusion}

This study provided proof-of-concept on the use of a platform composed of microfluidic chip together with fluorescence-labeled dendrimer NPs for the validation of new chemotherapeutic agents. In fact, the results show different responses to the presence of $0.5 \mathrm{mg} \mathrm{ml}^{-1}$ dendrimer NPs when comparing static with dynamic conditions, with a tendency toward higher sensitivity when subjected to confinement, flow and shear stress (dynamic conditions). Moreover, the observed high internalization rates of the NPs can be beneficial, making them excellent intercellular carrier of anticancer drugs. Thus, the microfluidics can enable the development of diagnostics platform and personalized therapies, as it opens the possibility to a valuable system to test and validate new chemotherapeutic agents in a more realistic manner, expediting its translation into clinic.

\section{Future perspective}

Recent evidence indicates that 3D and flow models more closely resemble in vivo function. For example, plenteous reports have shown improved functionality with 3D cultures and flow cultures for xenobiotic metabolism competence more closely mimicking in vivo levels. Therefore, as hypothesized by us, the proposed system has some important features representative of the in vivo microenvironment, such as confinement, flow and shear stress. This platform, together with the efficient ability of cell tracking and drug delivery, represents a new step toward dynamic studies in cancer cells in 3D, namely migration and drug testing. Hence, this work further shapes the challenges associated with the use of NPs to help deliver drugs more specifically and effectively to cancer cells as well as to help detect cancer (theranostics). Future NPs and microfluidic models can boost drug validation and the understanding of tumorigenesis processes, essential to move the cancer research field forward in terms of prevention, detection and treatment.

Financial \& competing interests disclosure

FR Maia acknowledges ERC-2012-ADG 20120216-321266 (ComplexiTE) for her Postdoc scholarship. JM Oliveira thanks Portuguese Foundation for Science and Technology (FCT) for his distinction attributed under the FCT Investigator program (IF/00423/2012). BM Costa also thanks Portuguese Foundation for Science and Technology (PTDC/SAU-GMG/113795/2009 and IF/00601/2012 to BM Costa), Fundação Calouste Gulbenkian (BM Costa) and Liga Portuguesa Contra o Cancro (BM Costa). MR Carvalho also thanks the funding through the LA ICVS/3Bs project (UID/Multi/50026/2013). The authors have no other relevant affiliations or financial involvement with any organization or entity with a financial interest in or financial conflict with the subject matter or materials discussed in the manuscript apart from those disclosed.

No writing assistance was utilized in the production of this manuscript.

\section{Ethical conduct of research}

The authors state that they have obtained appropriate institutional review board approval or have followed the principles outlined in the Declaration of Helsinki for all human or animal experimental investigations. In addition, for investigations involving human subjects, informed consent has been obtained from the participants involved. 
Executive summary

- The success of carboxymethylchitosan(poly)amidoamine dendrimer nanoparticle (NP) synthesis is confirmed through a series of physicochemical characterization techniques.

- Microfluidic chip Vena8 comprising shear stress and flow was used as a dynamic and physiologically relevant model.

- HeLa, HCT-116 and U87MG were used in this study to evaluate NP internalization level and cytotoxicity in a vast type of cancer cells.

- Higher internalization rates of the NPs were observed in dynamic conditions when compared with traditional static conditions.

- Different responses were observed regarding the presence of dendrimer NPs when comparing static with dynamic conditions, with a tendency toward higher sensitivity when subjecteded to confinement.

\section{References}

Papers of special note have been highlighted as: • of interest; •• of considerable interest

1 Siegel R, Ma J, Zou Z, Jemal A. Cancer statistics, 2014. CA Cancer J. Clin. 64(1), 9-29 (2014).

2 Ferlay J, Steliarova-Foucher E, Lortet-Tieulent J et al. Cancer incidence and mortality patterns in Europe: estimates for 40 countries in 2012. Eur. J. Cancer 49(6), 1374-1403 (2013).

3 Chaffer CL, Weinberg RA. A perspective on cancer cell metastasis. Science 331(6024), 1559-1564 (2011).

4 Headley MB, Bins A, Nip A et al. Visualization of immediate immune responses to pioneer metastatic cells in the lung. Nature 531(7595), 513-517 (2016).

5 Haley B, Frenkel E. Nanoparticles for drug delivery in cancer treatment. Urol. Oncol. 26(1), 57-64 (2008).

6 Valencia PM, Farokhzad OC, Karnik R, Langer R. Microfluidic technologies for accelerating the clinical translation of nanoparticles. Nat. Nanotechnol. 7(10), 623-629 (2012).

- This review paper was published in one of the most prestigious research journal, Nature Nanotechnology, and it tackles the recent use of microfluidic platforms for rapid screening of nanoparticles (NPs) and how it can be used to accelerate the clinical translation of NPs, which is what we are trying to do.

7 Popovtzer R, Agrawal A, Kotov NA et al. Targeted gold nanoparticles enable molecular CT imaging of cancer. Nano Lett. 8(12), 4593-4596 (2008).

8 Carvalho MR, Lima D, Reis RL, Correlo VM, Oliveira JM. Evaluating biomaterial- and microfluidic-based 3D tumor models. Trends Biotechnol. 33(11), 667-678 (2015).

- This recent paper is of interest because it reviews the use of biomaterials in tissue engineering approaches to emulate the extracellular matrix in combination with microfluidic devices.

9 Mestre T, Figueiredo J, Ribeiro AS, Paredes J, Seruca R, Sanches JM. Quantification of topological features in cell meshes to explore E-cadherin dysfunction. Sci. Rep. 6, 25101 (2016).

10 Sittampalam S, Eglen R, Ferguson S et al. Three-dimensional cell culture assays: are they more predictive of in vivo efficacy than 2D monolayer cell-based assays? Assay Drug Dev. Technol. 13(5), 254-261 (2015).
11 Bhatia SN, Ingber DE. Microfluidic organs-on-chips. Nat. Biotechnol. 32(8), 760-772 (2014).

12 Zhao L, Caot JT, Wu ZQ, Li JX, Zhu JJ. Lab-on-a-chip for anticancer drug screening using quantum dots probe based apoptosis assay. J. Biomed. Nanotechnol. 9(3), 348-356 (2013).

13 Zhou H, Zhao L, Zhang X. In-channel printing-device opening assay for micropatterning multiple cells and gene analysis. Anal. Chem. 87(4), 2048-2053 (2015).

14 Barata D, Van Blitterswijk C, Habibovic P. High-throughput screening approaches and combinatorial development of biomaterials using microfluidics. Acta Biomater. 34, 1-20 (2015).

15 Kuo CT, Chiang CL, Chang CH et al. Modeling of cancer metastasis and drug resistance via biomimetic nano-cilia and microfluidics. Biomaterials 35(5), 1562-1571 (2014).

16 Bischel LL, Young EW, Mader BR, Beebe DJ. Tubeless microfluidic angiogenesis assay with three-dimensional endothelial-lined microvessels. Biomaterials 34(5), 1471-1477 (2013).

17 Bray LJ, Binner M, Holzheu A et al. Multi-parametric hydrogels support $3 \mathrm{D}$ in vitro bioengineered microenvironment models of tumour angiogenesis. Biomaterials 53(0), 609-620 (2015).

18 Bersini S, Jeon JS, Dubini G et al. A microfluidic 3D in vitro model for specificity of breast cancer metastasis to bone. Biomaterials 35(8), 2454-2461 (2014).

19 Dong Y, Skelley AM, Merdek KD et al. Microfluidics and circulating tumor cells. J. Mol. Diagn. 15(2), 149-157 (2013).

20 Chen L, Chen B, Liu X et al. Real-time monitoring of a controlled drug delivery system in vivo: construction of a near infrared fluorescence monomer conjugated with $\mathrm{pH}$-responsive polymeric micelles. J. Mater. Chem. B 4(19), 3377-3386 (2016).

-• Of considerable interest because it tackles the goal of realtime monitoring of drug delivery systems using fluorescent micelles. Although it reports an in vivo strategy, they successfully synthesized the NPs and demonstrated the dynamic process of tumor treatment.

21 Kwak B, Ozcelikkale A, Shin CS, Park K, Han B. Simulation of complex transport of nanoparticles around a tumor using tumor-microenvironment-on-chip. J. Control. Release 194 157-167 (2014). 
-• This model, named tumor-microenvironment-on-chip, consists of 3D microfluidic channels where tumor cells and endothelial cells are cultured within extracellular matrix under perfusion of interstitial fluid. Also, it reveals interesting evidence that NPs should be designed considering their dynamic interactions with tumor microenvironment.

22 Fede C, Fortunati I, Weber V et al. Evaluation of gold nanoparticles toxicity towards human endothelial cells under static and flow conditions. Microvasc. Res. 97, 147-155 (2015).

- A very interesting paper that reports a similar model, in which they investigate gold NPs' uptake and toxicity toward endothelial cells in the presence of shear stress associated with a flowing medium, since these processes are normally present when NP formulations are intravenously administered. Interestingly, in this case, lower cytotoxicity was found in dynamic conditions.

23 Kesharwani P, Banerjee S, Gupta U et al. PAMAM dendrimers as promising nanocarriers for RNAi therapeutics. Mater. Today 18(10), 565-572 (2015).

24 Wolinsky JB, Grinstaff MW. Therapeutic and diagnostic applications of dendrimers for cancer treatment. Adv. Drug Deliv. Rev. 60(9), 1037-1055 (2008).

- This review article validates and reviews the characteristic of poly(amidoamine) dendrimer NPs as well as the progress that has been made toward the use of dendrimers for therapeutic and diagnostic purposes for the treatment of cancer.

25 Pojo M, Cerqueira SR, Mota T et al. In vitro evaluation of the cytotoxicity and cellular uptake of CMCht/PAMAM dendrimer nanoparticles by glioblastoma cell models. $J$. Nanopart. Res. 15(5), 1-9 (2013).

26 Chen X-G, Park HJ. Chemical characteristics of O-carboxymethyl chitosans related to the preparation conditions. Carbohydr. Polym. 53(4), 355-359 (2003).

27 Sashiwa H, Shigemasa Y, Roy R. Chemical modification of chitosan. Part 9: reaction of N-carboxyethylchitosan methyl ester with diamines of acetal ending PAMAM dendrimers. Carbohydr. Polym. 47(2), 201-208 (2002).

28 Oliveira JM, Kotobuki N, Marques AP et al. Surface engineered carboxymethylchitosan/poly(amidoamine) dendrimer nanoparticles for intracellular targeting. $A d v$. Funct. Mater. 18(12), 1840-1853 (2008).

29 Salgado AJ, Oliveira JM, Pirraco RP et al.
Carboxymethylchitosan/poly(amidoamine) dendrimer nanoparticles in central nervous systems-regenerative medicine: effects on neuron/glial cell viability and internalization efficiency. Macromol. Biosci. 10(10), 1130-1140 (2010).

30 Oliveira JM, Sousa RA, Kotobuki N et al. The osteogenic differentiation of rat bone marrow stromal cells cultured with dexamethasone-loaded carboxymethylchitosan/ poly(amidoamine) dendrimer nanoparticles. Biomaterials 30(5), 804-813 (2009).

31 Li Y, Tan Y, Xu K, Lu C, Liang X, Wang P. In situ crosslinkable hydrogels formed from modified starch and O-carboxymethyl chitosan. RSC Adv. 5(38), 30303-30309 (2015).

32 Martin-Rapun R, Marcos M, Omenat A, Barbera J, Romero P, Serrano JL. Ionic thermotropic liquid crystal dendrimers. J. Am. Chem. Soc. 127(20), 7397-7403 (2005).

33 Uppuluri S, Dvornic PR, Klimash JW, Carver PI, Tan NC. The properties of dendritic polymers I: generation 5 poly (amidoamine) dendrimers (1998). www.dtic.mil/dtic/tr/ fulltext/u2/a346880.pdf

34 Hui H, Xiao-Dong F, Zhong-Lin C. Thermo- and pHsensitive dendrimer derivatives with a shell of poly $(\mathrm{N}, \mathrm{N}$ dimethylaminoethyl methacrylate) and study of their controlled drug release behavior. Polymer 46(22), 9514-9522 (2005).

35 Sato M, Sasaki N, Ato M, Hirakawa S, Sato K, Sato K. Microcirculation-on-a-chip: a microfluidic platform for assaying blood-and lymphatic-vessel permeability. PLoS ONE 10(9), e0137301 (2015).

36 Kuete V, Fouotsa H, Mbaveng AT, Wiench B, Nkengfack AE, Efferth T. Cytotoxicity of a naturally occurring furoquinoline alkaloid and four acridone alkaloids towards multi-factorial drug-resistant cancer cells. Phytomedicine 22(10), 946-951 (2015).

37 Teh SY, Lin R, Hung LH, Lee AP. Droplet microfluidics. Lab Chip 8(2), 198-220 (2008).

38 Mahmood M, Casciano DA, Mocan T et al. Cytotoxicity and biological effects of functional nanomaterials delivered to various cell lines. J. Appl. Toxicol. 30(1), 74-83 (2010).

39 Carvalho MR, Lima D, Reis RL, Correlo VM, Oliveira JM. Evaluating biomaterial- and microfluidic-based 3D tumor models. Trends Biotechnol. 33(11), 667-678 (2015).

40 Horning JL, Sahoo SK, Vijayaraghavalu $S$ et al. 3-D tumor model for in vitro evaluation of anticancer drugs. Mol. Pharm. 5(5), 849-862 (2008). 